\title{
Formulando uma Psicopatologia Fundamental
}

\author{
Mario Eduardo Costa Pereira
}

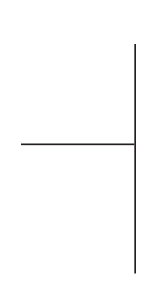

O presente trabalho busca situar a Psicopatologia Fundamental em relação ao contexto atual da psicopatologia e delimitar seu âmbito científico naquilo que ela traz de original na discussão psicopatológica.

Inicialmente, o campo da psicopatologia é estudado em relação à formalização proposta por Karl Jaspers em termos de uma psicopatologia geral. Em seguida, discute-se a incidência específica da psicanálise nesse debate.

Propõe-se que a tarefa da psicopatologia fundamental tem três frentes principais: 1) o trabalho de constante delimitação teórica entre as diversas disciplinas envolvidas no campo da psicopatologia, o que implica uma perspectiva histórica e crítica; 2) a teorização do papel dos modelos e paradigmas na constituição tanto do campo da psicopatologia quanto do dispositivo epistemológico de formalização do objeto psicopatológico; 3) resgate da dimensão de implicação subjetiva na constituição do sofrimento psíquico e estudo das perspectivas clínicas decorrentes de tal postura ético-epistemológica. 


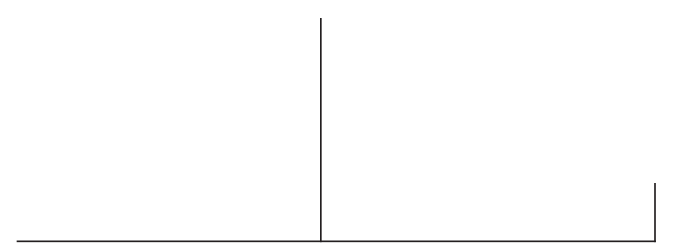

\section{Introdução}

O objetivo deste trabalho é tentar delinear o estado atual das concepções teóricas sobre a psicopatologia fundamental, situando esta nova disciplina em relação aos campos mais gerais e tradicionais da psicopatologia e da psicanálise, de maneira a permitir uma visão mais clara sobre o que ela propõe de original.

Para isso, será necessário, em primeiro lugar, traçar um panorama, mesmo que sucinto, da psicopatologia contemporânea, de modo a situar o contexto de onde emerge a psicopatologia fundamental.

\section{$O$ contexto atual da psicopatologia}

$\mathrm{Na}$ apresentação do primeiro número da Revue Internationale de Psychopathologie ${ }^{1}$, Pierre Fédida e Daniel Widlöcher assinalam que o termo "psicopatologia" refere-se atualmente a uma grande encruzilhada epistemológica na qual entrecruzam-se disciplinas científicas heterogêneas, que têm em comum a preocupação com o sofrimento psíquico. A maneira específica como cada uma delas define formalmente seu "objeto psicopatológico" e os procedimentos de pesquisa correspondentes variam de forma marcante, colocando assim o problema das condições de possibilidade para o diálogo intercientífico e para a confrontação crítica. Observa-se, por exemplo, o uso freqüente de uma terminologia psicopatológica comum sem que, no entanto, exista um mínino de

1. P. Fédida, D. Widlöcher. "Présentation". Revue Internationale de Psychopathologie, $\mathrm{n}^{\mathrm{o}} 1 / 1990$, pp. 3-4. 
$\begin{array}{lllllll}R & E & V & \text { I } & S & T & A\end{array}$

LATINOAMERICANA

DE PSICOPATOLOGIA

FUN D A M EN T A L

concordância quanto aos conteúdos semânticos a que se referem. Assim, o recorte particular que as neurociências fazem, por exemplo, da chamada "depressão" pode não ter qualquer correspondência com a abordagem analítico existencial ou comportamental dessa entidade, nem mesmo quanto à delimitação do fenômeno a que se referem. Não é, portanto, de estranhar que a expressão "torre de Babel" seja empregada tão freqüentemente pelos autores preocupados em descrever o estado atual da psicopatologia. ${ }^{2}$

A proposta atualmente hegemônica no que diz respeito às tentativas de se superar os impasses decorrentes da pluralidade de disciplinas neste campo é, sem dúvida, a que estipula uma definição empírico-pragmática das entidades psicopatológicas. Seu representante mais ilustre é o Manual de Diagnóstico e Estatística da Associação Psiquiátrica Americana, em sua quarta revisão (DSM-IV). Segundo essa corrente, a tarefa mais urgente da psicopatologia é obter um acordo mínimo quanto à definição das categorias diagnósticas, de modo que haja uma concordância entre as diversas disciplinas pelo menos no plano descritivo.

Dentro dessa perspectiva, dado que de qualquer forma os diagnósticos são meras convenções de caráter pragmático - mas convenções de grande importância, uma vez que constituem a base de todo o processo clínico e de pesquisa - é necessário que os critérios de definição dessas categorias sejam claramente explicitados. Não se trata mais de tentar exprimir ou descrever a essência do sofrimento humano, nem mesmo especular sobre suas possíveis determinações, o que aproximaria a psicopatologia perigosamente da metafísica. Busca-se, antes de mais nada, o ideal de um acordo mínimo com relação à delimitação formal e operacional das categorias diagnósticas empregadas. Tal delimitação deve estar fundada em critérios empíricos minuciosamente definidos, universalmente válidos e formulados de forma que não deixem margens a ambigüidades. É assim que o DSM-IV e as demais classificações operacionais de transtornos mentais propõem critérios explícitos tanto para a inclusão de uma determinada constelação de sintomas clínicos em uma de suas categorias diagnósticas, como para a sua exclusão. Além disso, é preciso que um tal procedimento classificatório não se deixe influenciar pelas teorias psicopatológicas ainda não suficientemente ratificadas por procedimentos empíricos e experimentais. Nesse particular, busca-se o ideal da renúncia aos a priori teóricos; daí tais sistemas se autoproclamarem como sendo "ateóricos".

Se é verdade que tal forma de abordagem do objeto psicopatológico tem proporcionado progressos incontestáveis em certos campos de pesquisa, notadamente naqueles que se fundamentam em uma abordagem empíricoexperimental, tais como a psicofarmacologia, a epidemiologia e as neurociências

2. Cf., p. ex., S. Ionescu. Quatorze approches de la psychopathologie. Poitiers, Nathan, 1991. 


\section{ARTIGOS}

em geral, por outro lado, ela tem-se mostrado absolutamente ineficaz, ou mesmo nociva, para as disciplinas que não se adaptam ao modelo das ciências naturais. Tal é o caso da psicanálise e da análise existencial, por exemplo. Considerandose que a abordagem empírico-operacional em psicopatologia tornou-se uma espécie de versão obrigatória no plano cultural para a aceitabilidade de uma disciplina nesse campo, ela acabou por marginalizar certos discursos tradicionalmente de grande importância nesse debate.

$\mathrm{Na}$ tentativa de permitir uma melhor comunicação intercientífica e maior eficácia da pesquisa nesse campo, essa abordagem acabou, de fato, por impor uma epistemologia e uma metodologia de cunho pragmático e experimental ao conjunto das disciplinas implicadas na psicopatologia.

Surge assim, de forma mais aguda nesse final de século, a necessidade de uma disciplina que contribua para a redefinição do campo psicopatológico, distinguindo seu plano pragmático de seu plano propriamente fundamental, interessando-se pelo estudo dos modelos e paradigmas de cada disciplina e, sobretudo, redefinindo novos objetos de pesquisa que justamente levem em conta a dinâmica dos novos conhecimentos produzidos em psicopatologia e certas dimensões fundamentais da experiência do padecimento mental, tais como a da subjetividade e a da implicação existencial do sintoma.

Pode-se, sem dúvida, argumentar que não há outro plano de legitimidade para a psicopatologia que não seja o pragmático, uma vez que o objeto psicopatológico não tem qualquer consistência em si mesmo, tratando-se apenas de uma construção teórica, visando resultados heurísticos e práticos. Contudo, não se pode esquecer que o pragmatismo que está efetivamente em questão nos dias atuais está impregnado de uma visão empiricista do sofrimento psíquico, seja o que for que se defina por este termo, deixando de fora dimensões éticas e práticas significativas.

Torna-se necessário, portanto, retomar as bases teóricas da psicopatologia, tal como constituída teórica e historicamente, de maneira a discernir o horizonte de seus fundamentos. O que não implica conceber qualquer consistência ontológica nesses fundamentos. Trata-se, antes de mais nada, de evidenciar as questões e problemas que lhe dão pertinência e significação.

\section{O campo da psicopatologia segundo Jaspers}

A constituição da psicopatologia como disciplina científica formalmente estruturada surge no começo deste século com a publicação da Allgemaine Psychopathologie (Psicopatologia geral), de Karl Jaspers, em 1913. Trata-se da primeira tentativa de se dar uma base teórica à psicopatologia e constitui, desde 
$\begin{array}{lllllll}R & E & V & \text { I } & S & T & A\end{array}$

LATINOAMERICANA

DE PSICOPATOLOGIA

F U N D M N T A L

então, a referência central a tudo o que se desenvolveu nesse campo. O conhecimento dessa obra é indispensável para que se possa situar de forma consistente a proposta de uma psicopatologia fundamental.

A introdução do livro de Jaspers situa de forma precisa o projeto a ser desenvolvido:

O objeto da psicopatologia é o fenômeno psíquico realmente consciente. Queremos saber o que os homens vivenciam e como o fazem. Pretendemos conhecer a envergadura das realidades psíquicas. E não queremos investigar apenas as vivências humanas em si, mas também as condições e as causas de que dependem os nexos em que se estruturam, as relações em que se encontram, e os modos em que, de alguma maneira, se exteriorizam objetivamente. Mas nem todos os fenômenos psíquicos constituem nosso objeto. Apenas os "patológicos"3

Apesar desse recurso à categoria de "patológico", a psicopatologia jasperiana propõe-se a ser uma ciência autônoma, absolutamente independente da psiquiatria. Jaspers afirma, de forma um tanto paradoxal, que "não damos nenhum valor a um conceito preciso de enfermidade mental e, na escolha do material, atemo-nos sobretudo ao costume da divisão de trabalho até aqui em vigor." ${ }^{4}$ Essa "divisão de trabalho" refere-se implicitamente, em primeiro lugar, à distinção entre psicologia que trata do psiquismo normal e psicopatologia que trata do "patológico". Em segundo lugar, ela implica que as categorias "patológicas" que constituem o objeto da psicopatologia geral são, na verdade, delimitadas pela clínica psiquiátrica tradicional. E isso não impede, aos olhos de Jaspers, que a psicopatologia constitua a base teórica da psiquiatria, sem com ela confundir-se, assim como a cirurgia não se confunde com a anatomia que, contudo, a fundamenta.

A psicopatologia de Jaspers sustenta-se na fenomenologia. Desse fato, o eixo de sua atenção focaliza-se nas manifestações da consciência, tentando descrever da forma mais precisa possível aquilo que o sujeito realmente vivencia, em seu estado mental, enquanto dado imediato da consciência. Ela busca captar o psíquico tal como ele é, evitando metodologicamente toda a influência a priori das teorias sobre possíveis leis e mecanismos que ordenariam o psiquismo. Busca-se o contato mais direto possível com a coisa mesma do sofrimento mental. Isso só é possível a partir do psiquismo do próprio psicopatólogo exposto a um contato profundo e aberto ao sofrimento de outrem.

Numa acepção mais estrita, a psicopatologia procura apreender a Erlebnis patológica do paciente psíquico. Na tradição fenomenológica, a Erlebnis constitui uma das formas da "experiência", referindo-se à vivência subjetiva enquanto tal.

3. K. Jaspers (1913). Psicopatologia geral. Vol. I. Rio de Janeiro, Atheneu, p. 13.

4. Idem. 


\section{ARTIGOS}

Nisso, ela se distingue tanto da Erfahrung, a qual enfatiza aquilo que uma experiência permite de apreensão de um certo objeto, como do Experimentz, que se refere a uma abordagem cientificamente organizada ao objeto, de uma tal maneira que permite que se testem hipóteses previamente formuladas a seu respeito. Esta é a forma de experiência própria às ciências experimentais. Assim, a psicopatologia geral busca descrever com a Erlebnis específica às diferentes formas de sofrimento psíquico, aquilo que o sujeito efetivamente vivencia.

É sabido que Jaspers, esse discípulo de Husserl, retoma a clássica distinção introduzida por Dilthey entre o "explicar" (Erklären) e o "compreender" (Verstehen). Preocupado em definir os métodos próprios a cada ciência, Dilthey concebia a explicação como o procedimento essencial da ciência da natureza (Naturwissenschaften). Estas deveriam abordar seus objetos de pesquisa de forma a extrair as leis que determinassem de forma necessária os fenômenos por eles implicados. Seu objetivo é explicar os fenômenos em termos de causalidade. Já as ciências do espírito (Geistwissenschaften), incapazes de conferir a mesma precisão a seus objetos, deveriam esforçar-se para estabelecer as conexões de sentido entre os fenômenos sutis do espírito, de modo a tornar acessível sua lógica interna.

A compreensão, no sentido de Jaspers, é utilizada como método e como propósito de suas investigações psicopatológicas. Logo de saída, ele introduz uma delimitação fundamental na abrangência de sua abordagem compreensiva. O grande psicopatólogo de Heidelberg sustenta que a psicopatologia trata de fenômenos humanos e que o homem é irredutível às propostas de compreensão que se possa dele fornecer. Dessa maneira, a compreensão jasperiana implica um método aproximativo que visa captar o sentido das experiências daquele que sofre. Ela é aproximativa pois, tal como pensa Jaspers, o homem é irredutível à objetividade conceitual. A compreensão não tem a mesma força de convicção de uma demonstração causal empírica, mas é mais apropriada para a natureza do fenômeno psíquico.

Jaspers introduz também uma distinção entre a compreensão estática e a compreensão genética. Enquanto aquela visa apreender o estado psíquico atual, tal como vivido pelo sujeito, esta tenta abranger as conexões de sentido entre os diversos momentos históricos daquela existência de modo a extrair os nexos internos que levaram à implantação do estado atual.

Sua distinção fundamental entre "desenvolvimento" e "processo" baseiase nesse ponto de vista diacrônico. O desenvolvimento refere-se a condições psicopatológicas compreensíveis em termos de encadeamentos de vivências que acabaram por conduzir ao estado atual. Diferente é o processo, o qual surge como aquilo que Jaspers chama de uma "ruptura na curva vital", ou seja, o estado atual é irredutível pelo método compreensivo, ele não se deixa apreender 
$\begin{array}{lllllll}R & E & V & \text { I } & S & T & A\end{array}$

LATINOAMERICANA

DE PSICOPATOLOGIA

FUND A M EN T A L

psicogeneticamente. Ele aparece como uma irrupção estranha ao encadeamento dos fatos vitais daquela existência. Com o processo rompe-se o ciclo das compreensões genéticas. É assim que Jaspers define os chamados delírios primários ou verdadeiros, como rupturas incompreensíveis eclodindo no interior de uma existência.

Alguns psicopatólogos leitores de Jaspers viram nessas descontinuidades uma evidência de que os processos delirantes em questão não poderiam ser de origem intrapsíquica, devendo ser pensados como a intrusão de conteúdos patológicos por uma disfunção de natureza orgânica. Eles não poderiam ser compreendidos em termos de sentido. Eles deveriam, isso sim, ser explicados em termos estritamente médicos. Tal equivalência entre "não-sentido" e "biológico" não está presente na Psicopatologia geral.

Certas nuances da psicopatologia fenomenológica de Jaspers são melhor compreendidas quando confrontadas à Daseinanalyse de Binswanger. Embora ambas trabalhem com um método fenomenológico, a psicopatologia geral de Jaspers esforça-se para descrever a experiência da consciência psicopatológica, enquanto a abordagem de Binswanger propõe-se a descrever o "mundo" do Dasein em padecimento, em suas dimensões de contingência, fatualidade e de ser-paraa-morte. Na análise que faz Binsawanger da melancolia ${ }^{5}$, por exemplo, sua preocupação não é apenas a de descrever as vivências típicas desses pacientes, mas de delimitar as alterações em suas dimensões existenciais, como no caso da temporalidade. Binswanger chama a atenção para o fato de que uma das características da temporalização do melancólico é a de que todas as possibilidades de abertura em relação ao futuro (protenção) apresentam-se como já tendo sido irremediavelmente esgotadas no passado (retenção), de modo que o mundo do melancólico apresenta-se como que exaurido de possibilidades.

A importância da psicopatologia inaugurada por Jaspers no estudo do sofrimento psíquico é mais nítida quando se analisa a ruptura que ela constitui com a abordagem psiquiátrica de seu tempo e a repercussão que teve sobre a psiquiatria atual e sobre a concepção contemporânea do sofrimento mental. Desde o século XVIII, com o surgimento da psiquiatria de Pinel, a medicina passou a constituir o discurso autorizado sobre os fenômenos patológicos próprios à alma, rompendo-se, assim, a visão religiosa predominante desde a Idade Média. Tornava-se necessário descrever e classificar com precisão as diversas formas do sofrimento psíquico e da loucura.

Nessa vertente, a obra de Kraepelin foi decisiva por oferecer à psiquiatria uma base racional solidamente ancorada na experiência clínica e na observação dos fatos. Para o psiquiatra alemão, a psiquiatria opera através da semiologia, a

5. L. Binswanger (1960). Mélancolie et manie. Paris, PUF, 1987. 


\section{ARTIGOS}

qual tem a incumbência de resgatar da clínica os principais sinais e sintomas das doenças mentais. A tarefa propriamente teórica e científica da psiquiatria é a de constituir uma nosologia e uma nosografia, ou seja, uma descrição precisa das entidades mórbidas e um sistema de classificação que introduzisse uma racionalidade em suas relações.

A própria noção de "entidade mórbida" no sentido médico, para designar um fenômeno psicopatológico particular, só vai consolidar-se a partir da obra kraepeliniana. É claro que, nessa vertente, Kraepelin conta com ilustres percussores como Jean-Pierre Falret e Magnan, na França, e Kahlbaum e mesmo Hecker, na Alemanha. Contudo, a tradição psiquiátrica herdada de Pinel e de Esquirol contentava-se com a descrição de certas regularidades clínicas, com um estatuto que poderíamos qualificar de "síndromes" ou mesmo de "transtornos morais", para ficarmos na visão pineliana. A ampla aceitação da idéia de "doença mental" só será consolidada a partir de Kraepelin.

Sua abordagem do sofrimento mental era, portanto, eminentemente descritiva e classificatória, visando a descrição mais precisa possível das ditas "entidades mórbidas" e sua clara discriminação no plano clínico. Sua maneira de conceber a abordagem científica do sofrimento psíquico sustenta-se na ênfase, na descrição precisa e na classificação pertinente. Essa supõe um raciocínio comparativo arguto, de modo a distinguir do ponto de vista clínico e da evolução do processo mórbido, as diversas entidades nosológicas da psiquiatria. Kraepelin pressupõe que as doenças mentais têm consistência própria, são independentes do observador e dão-se a conhecer através da clínica apurada. Daí decorre que os estudos a respeito da patogenia e da terapêutica só poderiam ser cientificamente fundados a partir desse trabalho nosográfico preliminar. A fisiopatologia das doenças psiquiátricas só poderiam se desenvolver se houvesse uma sólida nosografia para sustentá-la.

Com Jaspers, vemos o surgimento da psicopatologia como disciplina científica, não-médica, mergulhada no particular da experiência íntima do sofrimento individual e ainda assim preocupada em produzir proposições de caráter geral sobre as formas específicas do padecer psíquico.

É interessante ressaltar que a tensão teórica entre a abordagem médica de inspiração kraepeliana e a abordagem fenomenológica de Jaspers atualiza-se de forma bastante concreta na mesma cidade de Heidelberg, em torno do debate sobre o estatuto epistêmico a conceder à psicopatologia. Esse desacordo concerne justamente Jaspers e o chefe da cadeira de Psiquiatria de quem era assistente. Seu nome: Kurt Schneider. Schneider é um nome imortal da psiquiatria, conhecido sobretudo por ter descrito os chamados "sintomas de primeira ordem" da esquizofrenia. Em seu livro mais conhecido - Psicopatologia clínica $^{6}-$, ele

6. K. Schneider (1948). Psicopatologia clínica. São Paulo, Mestre Jou, 1976. 
$\begin{array}{lllllll}R & E & V & \text { I } & S & T & A\end{array}$

LATINOAMERICANA

DE PSICOPATOLOGIA

F U N A MEN T A L

sustenta que corre-se o risco de imprecisão ao se utilizar o termo "psicopatologia" em psiquiatria, pois, segundo o mestre alemão, "a alma não pode adoecer." Apenas o corpo é susceptível de ser atingido pela doença, de onde emerge sua máxima: "a enfermidade só existe no corporal".

Trata-se de uma bem-vinda precisão terminológica uma vez que assistimos, mesmo nos dias de hoje, um sutil deslizamento semântico do pathos implicado na psicopatologia que tende a igualá-la a uma psiconosologia.

\section{Da "generalidade" da psicopatologia geral}

No quadro da psicopatologia geral de Jaspers, interessa-nos elucidar o tipo de "generalidade" que é visada nesse projeto. Pierre Fédida ocupou-se dessa importante questão em um artigo intitulado "D'une psychopathologie générale à une psychopathologie fondamentale. Note sur la notion de paradigme"7.

O problema da generalidade na psicopatologia jasperiana suscita questões cruciais, sendo que algumas delas interessam diretamente à psicanálise. Em uma primeira aproximação de caráter mais amplo pode-se colocar o problema nos seguintes termos: que tipo de generalização é possível extrair de uma abordagem que visa precisamente atingir o mais singular da experiência do sofrimento de cada um, tal como propõe a mirada fenomenológica de Jaspers? Tentaremos responder essa questão, ainda que de uma forma aproximativa.

A fenomenologia, como concebida por Husserl, é uma ciência eidética, ou seja, uma disciplina que se interessa pelas essências. Assim como exprime o leitmotiv do projeto husserliano, trata-se de um retorno às coisas mesmas, tal como elas dão-se a conhecer no plano da consciência, de forma imediata, antes de qualquer teoria organizadora. Seu método consiste, portanto, quando aplicado a questões clínicas, em olhar, olhar e olhar até que haja a possibilidade da incorporação do observador no objeto considerado. Nesse momento ocorreria uma tomada direta de consciência ou, pelo menos, uma visão privilegiada, de natureza intuitiva, da essência em questão.

O tipo de generalidade decorrente de tal procedimento é nomeado por Husserl de "intuição categorial", de modo que as essências assim apreendidas pela exposição ao fenômeno podem ser descritas e organizadas em gêneros e espécies que não têm, eles mesmos, qualquer existência real pois referem-se a estados da consciência, mas que podem ser pensados em sua generalidade transcendental.

7. P. Fédida. "D’une psychopathologie générale à une psychopathologie fondamentale. Note sur la notion de paradigme", in P. Fédida. Crise et contre-transfert. Paris, PUF, 1992. 


\section{ARTIGOS}

Aqui haveria uma distinção maior entre as ciências da natureza e a fenomenologia. Enquanto aquelas ocupam-se de objetos realmente presentes e que funcionam independentemente do observador, prestando-se assim a uma abordagem empírico-experimental, esta liga-se aos fenômenos e às formas particulares da consciência em seu caráter intencional. A fenomenologia limitase, portanto, ao que pode ser vivido e apreendido no plano da consciência. Daí entende-se como os problemas que levaram Husserl à criação da fenomenologia foram justamente aqueles suscitados por suas investigações no campo da matemática e da geometria. Na geometria, trata-se de essências puras.

No plano das aplicações dessa distinção no campo que nos interessa, a psicologia surgiria como o protótipo da ciência empírico-experimental e a psicopatologia geral jasperiana, o protótipo da ciência eidética.

Fédida constata que a psicopatologia geral não cria propriamente uma nova nosologia. Ela, antes, refere-se às entidades clínicas da psiquiatria clássica, buscando apreender a natureza da experiência existencial que elas implicam. Tratando-se de uma disciplina fenomenológica, a psicopatologia geral busca atingir o eidos das diferentes formas do padecimento humano. Mais concretamente, trata-se de apreender as essências fenomenológicas implicadas nas diversas formas de sofrimento psíquico, de maneira a descrever o "tipo psicopatológico" próprio a cada uma delas. Ela visa uma idealidade transcendental, de nítida inspiração platônica. Ou seja, seu objetivo é produzir modelos prototípicos das vivências próprias aos diversos quadros clínicos da psiquiatria. Vemos, aqui, uma imbricação muito mais profunda da fenomenologia jasperiana e da psiquiatria do que a proposta da psicopatologia geral permitiria entrever numa primeira aproximação.

Contudo, as coisas não são muito diferentes em psicanálise no que diz respeito às zonas de sobreposição de suas próprias noções psicopatológicas com as das psiquiatria.

As relações da psicanálise com a tradição psiquiátrica são, também, muito mais complexas do que gostariam aqueles que sustentam uma oposição radical dos discursos da psicanálise e da medicina. O objetivo aqui não é o de contestar o interesse teórico e clínico dessa distinção, mas apenas o de insistir sobre o caráter problemático no estabelecimento dessas fronteiras. Pode-se mesmo afirmar que este é um campo constante de pesquisa, que interessa precisamente uma psicopatologia fundamental e que de forma alguma está demarcado de uma vez por todas.

Que Freud tenha instaurado um corte epistemológico radical entre as abordagens médica e psicanalítica na abordagem do sofrimento humano parece pouco contestável. Contudo, as coisas se complicam quando introduzimos uma visão histórica e crítica mais aguçada. Lembremos apenas alguns elementos essenciais. 
$\begin{array}{lllllll}R & E & V & \text { I } & S & T & A\end{array}$

LATINOAMERICANA

DE PSICOPATOLOGIA

FUND A M ENT A L

Freud, médico e pesquisador de ciências naturais de formação, entra no campo da psicopatologia pela via da histeria. Sua formação estritamente psiquiátrica ocorreu no Hospital Geral de Viena, no serviço de Meynert, por um período não superior a seis meses, durante o ano de 1883. É importante lembrar que a doutrina psiquiátrica de Meynert, este destacado representante da psiquiatria organicista e associacionista de sua época, era uma espécie de referência obrigatória a todo o estudante de psiquiatria de língua alemã na virada do século. Ou seja, Freud teve sua iniciação psiquiátrica dentro da tradição mais clássica.

No campo específico da psicopatologia, sabe-se que Freud deu contribuições consistentes para a constituição da nosologia psiquiátrica atual, criando categorias que foram rapidamente incorporadas pela psiquiatria de sua época e que persistem até hoje. Entre elas, destacam-se a descrição clínica da neurose de angústia e da neurose obsessivo-compulsiva. Mesmo a chamada histeria de conversão, tão conhecida de qualquer psiquiatra, pode ser considerada como oriunda do trabalho freudiano no campo da histeria. Sabe-se bem o enorme esforço que as modernas classificações psiquiátricas empregam para apagar as marcas da psicanálise na nosografia psiquiátrica. O aparecimento dos modernos "transtorno obsessivo-compulsivo", "transtorno conversivo" e mesmo dos famosos transtornos de "pânico" e de "ansiedade generalizada" não é senão uma tentativa de "purificação ideológica" de sistemas classificatórios modernos, que se pretendem "ateóricos" e "operacionais" e que buscam se livrar de seu incômodo passado freudiano.

Por outro lado, Freud serviu-se amplamente da psiquiatria de seu tempo em seu esforço de abordagem psicanalítica de questões psicopatológicas. O termo "dementia paranoides" do qual se serve Freud já no título de seu famoso trabalho sobre o presidente Schreber é retirado diretamente da nosografia de Kraepelin. Segue-se, ao longo do texto, um longo debate acerca do diagnóstico de Schreber fundado sobre critérios estritamente psiquiátricos. Trata-se de uma paranóia ou de parafrenia? Que consequiências haveria para a psicanálise se não fosse uma dessas categorias psiquiátricas e sim outra? Ou ainda uma terceira?

O mesmo coloca-se para a melancolia. A melancolia sobre a qual debruçase Freud não é outra senão aquela recortada ao longo de toda a tradição médica, desde Hipócrates até Kraepelin, passando por Esquirol (e sua "lipemania") e por Falret (e a folie à double forme).

$\mathrm{O}$ quadro fica ainda mais complicado quando pensamos em entidades de ampla aceitação psiquiátrica e, diríamos mesmo, verdadeiros ícones da psiquiatria biológica contemporânea cuja descrição foi profundamente marcada pela psicopatologia psicanalítica. Pensamos aqui, naturalmente na esquizofrenia.

O próprio termo "esquizofrenia" foi cunhado por Bleuler num contexto de profunda interlocução com a psicanálise freudiana. Sua idéia central de uma 


\section{ARTIGOS}

patologia organizada em torno da clivagem, da dissociação das diversas partes constituintes da personalidade derivam diretamente de uma leitura psicanalítica da psicopatologia da dementia praecox kraepeliniana. Influenciado pelo método de associação de idéias desenvolvido juntamente com Jung e pela observação deste de que se poderia fundar uma psicopatologia em torno dos complexos particularmente implicados em cada transtorno mental ${ }^{8}$, Bleuler resolve aplicar essa abordagem em seus pacientes diagnosticados como dementes precoces. Sua constatação não pode ser mais surpreendente. O investimento afetivo que estes indivíduos faziam em certos complexos era de tal monta que inviabilizava qualquer outro investimento, seja no sentido da integração da personalidade, seja no comércio com o mundo externo. A esse abissal ensimesmamento, considerado por Bleuler como constituindo o núcleo psicopatológico da esquizofrenia, foi dado o nome de autismo. Estavam lançadas as bases da problemática que levaria à teorização do narcisismo em psicanálise e à busca dos sintomas primários, irredutíveis psicologicamente, pela psiquiatria. O texto fundador da esquizofrenia como entidade clínica, Demência precoce - O grupo das esquizofrenias ${ }^{9}$, aparece em 1911, o mesmo ano em que Freud publica seu comentário sobre as memórias do "Presidente Schreber". Deve-se ressaltar que a inovação introduzida por Bleuler foi menos descritiva do que psicopatológica. A "schizo" que estava em jogo era menos uma observação clínica do que uma proposta de leitura psicanalítica da psicopatologia da dementia praecox.

Dessa forma, constata-se que a psiquiatria contemporânea usa como paradigma psicopatológico um transtorno mental cuja descrição tem por interlocutores fundamentais além do próprio Bleuler, Kraepelin, Freud, Jung e Abraham. Terrível constatação para aqueles que gostariam que a separação entre as psicopatologias psicanalítica e psiquiátrica fosse algo simples e quase autoevidente.

O que ocorre de fato no plano psicopatológico é, pois, uma profunda imbricação entre esses dois campos, cuja elucidação é por si própria uma fonte de aprofundamento do objeto psicopatológico e uma tarefa da psicopatologia fundamental. Disso decorre que a psicopatologia fundamental é indissociável de um debate constante com a história da psicopatologia. Evidentemente sua tarefa não se esgota na recuperação das lições da história, mas provavelmente esse diálogo será extremamente saudável e fecundo para o desenvolvimento de sua atividade crítica.

8. Cf. M. Menuck. "What did Eugen Bleuler really say?". Canadian Journal of Psychiatry, 1979, 24, pp. 161-166.

9. E. Bleuler (1911). Demencia precoz - el grupos de las esquizofrenias. Buenos Aires, Paidós. 


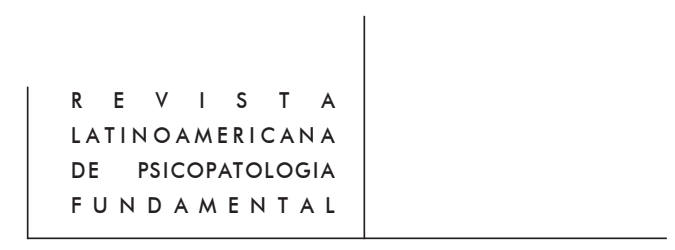

\section{Psicopatologia fundamental e psicanálise}

A psicanálise, por sua vez, instaura a dimensão da subjetividade no centro da psicopatologia, o que embaralha consideravelmente as variáveis do jogo. Em primeiro lugar, ela vai colocar em questão a própria legitimidade de outras disciplinas pretenderem tratar do psicopatológico como um fato objetivo, à moda das ciências naturais. Ela vai denunciar no empirismo, em primeiro lugar, a ilusão de isenção do observador em relação ao fato observado e, em se tratando de psicopatologia, ela vai afirmar que não há, a propriamente falar, qualquer fato a observar, pois o que está em questão não são os eventuais sintomas do sofrimento anímico, mas um discurso pronunciado em torno de uma queixa de falta de gozo.

À fenomenologia, a psicanálise vai contestar a possibilidade de qualquer compreensão da dor do outro, pois, naquilo que tem de essencial, ela é totalmente irredutível às minhas próprias imagens do sofrer, a não ser por um processo de profunda ilusão que não se reconhece como tal. A compreensão genética estaria mais próxima do imaginário que faz do eu o denominador comum de todo o universo, sendo tudo, em última instância, passível de ser reduzido a eu. O que é irredutível, não pertenceria ao universo.

Tomando uma posição crítica tão extremada, a psicanálise corre o risco de um fenomenal isolamento narcísico, colocando-se como único discurso válido para tratar do psicopatológico, perdendo assim o fator revigorante da dialética e do debate com interlocutores externos.

Aqui, também, parece-me que se esconde um profundo mal-entendido. Tomemos, por exemplo, o recurso do qual se serve Freud para tentar dar conta justamente da psicopatologia da histeria, no contexto do Projeto de 1895. O Projeto de Freud esforça-se por ser absolutamente realista. É uma busca por descrever todos os fenômenos relativos ao funcionamento psíquico em termo de "neurônios" e de "uma energia Q $\eta$ sujeita às leis do movimento". Não se discute aqui a eventual intenção realista de Freud. É suficiente constatar, com Osmyr Faria Gabbi Jr., o fracasso desse intento, que se torna evidente no curso do próprio texto, quando, por exemplo, Freud tem que dar conta do problema da consciência. Contudo, apesar do evidente malogro de seu Projeto, o recurso aos modelos da neurologia de seu tempo, ainda que um pouco fantástica em certos momentos, por vezes em avanço ou em retardo em relação ao que já se conhecia na época, permitiu a Freud exprimir, de alguma maneira, teses decisivas oriundas de sua experiência clínica com a histeria, muitas das quais seriam retomadas ao longo de toda sua obra.

Mais evidente é o uso que faz Freud de modelos pretensamente históricos e antropológicos para situar, de forma mítica, a origem da lei paterna e da 


\section{ARTIGOS}

interdição do incesto. Aqui, "Totem e tabu" constitui o exemplo paradigmático da construção de um mito para dar conta de certas recorrências observadas na situação psicanalíticas, que para serem pensadas globalmente, necessitavam de um instrumento de valor heurístico que constituísse uma prototeoria. Aqui, o recurso a uma antropologia fantástica fornece um modelo para a elaboração teórica de uma questão psicanalítica.

O mesmo pode-se dizer de Lacan e de seu recurso sucessivos à lingüística, à lógica e à topologia para formalizar a psicanálise e os mitos freudianos. Ou quando pensamos nos três modelos de Bion - lógico-matemático, estético e místico-religioso - para dar conta da experiência analítica. Estes são apenas três exemplos de situações de recursos a "formas de pensar" importadas (naturalmente com deformações) de outros campos, constituindo um processo que não está à margem da elaboração metapsicológica, mas que, justamente ao contrário, constitui seu próprio cerne.

A psicanálise lida com um objeto que não tem consistência empíricoexperimental, mas que surge como necessidade lógica para tornar apreensível no plano discursivo a experiência clínica de uma cura pela palavra que se dá na situação analítica. Ou seja, para poder dar conta de seu objeto, a psicanálise precisa, como qualquer outra disciplina, estar atenta aos modelos e paradigmas das ciências que a circundam. Nesse sentido, uma psicopatologia fundamental não poderia em nenhum caso ser uma psicopatologia "fundamentalista", que confunda rigor com ortodoxia cega.

Isso funciona nos dois sentidos e é muito bem possível que modelos intrinsecamente psicanalíticos possam servir de substrato heurístico para que sejam pensados problemas de outras disciplinas. É assim que vemos, hoje em dia, Francisco Varela, famoso diretor de pesquisas do Centro Nacional de Pesquisas Científicas da França, recorrer às teorias psicanalíticas sobre a identidade e a identificação para renovar as metáforas sobre as quais funda-se o pensamento da imunologia, uma vez que as metáforas bélicas clássicas, de um organismo submetido ao ataque de inimigos, dos quais ele deveria se defender e aprender reagir o mais prontamente possível, começaram a mostrar-se insuficientes. A imunologia passou a deparar-se com questões para as quais seus modelos habituais já não eram mais capazes de fornecer o suporte referencial para que estas pudessem ser pensadas e elaboradas.

Dessa forma, aparece aqui uma outra dimensão da psicopatologia fundamental, qual seja a de desenvolver uma teoria das modelizações e dos paradigmas no campo do estudo do sofrimento psíquico, discutindo suas possibilidades de avanço e os limites impostos pela própria capacidade metaforizante dos modelos escolhidos. 
$\begin{array}{lllllll}R & E & V & \text { I } & S & T & A\end{array}$

LATINOAMERICANA

DE PSICOPATOLOGIA

FUN D A M EN T A L

Finalmente, é preciso ressaltar que a psicanálise recupera a dimensão propriamente pática implicada no termo de "psicopatologia". O pathos grego, em sua dupla dimensão de paixão e de sofrimento passivamente experimentado, sofre um deslizamento semântico quando apropriado pela tradição médica, sendo igualado ao nosos, a doença que surge por uma alteração na materialidade do corpo. Tal deslizamento faz com que a psicopatologia passe a ser confundida com uma psiconosologia, restringindo assim seu âmbito teórico ao de uma disciplina interessada na descrição, classificação e nos mecanismos subjacentes às doenças mentais. Correlativamente a isso, o sujeito fica excluído de implicação em seu sofrimento.

Os trabalhos de Pierre Fédida ${ }^{10}$ e de Manoel Berlinck ${ }^{11}$ mostram que, mesmo antes de constituir-se como uma disciplina específica formalmente delimitada, a psicopatologia já existia sob a forma de uma tradição que surge com os gregos, e, sobretudo, com o teatro de Ésquilo, que vê na paixão (pathos) um sofrimento que comporta a possibilidade de transformar-se em sabedoria (pathei mathos), à condição de poder ser escutado por um outro que sustente a palavra do sofredor até que ela atinja seus extremos de autoengendramento de um sujeito.

Isaías Pessotti faz um belo comentário sobre a Atè grega em seu livro A loucura e as épocas ${ }^{12}$. Ele mostra que em Homero a Atè, a loucura sagrada, referese a um estado transitório de insensatez produzido pela divindade. Existiam, também, os processos de possessão pelos deuses, conhecidos como "teolepsias", ou pelas Musas dos quais geralmente resultava um estado de inspiração ou de iluminação. Não havia, pois, motivo de culpa ou de remorso pela própria loucura, uma vez que essa dependia essencialmente da vontade soberana dos deuses.

Porém, tudo se passava diferentemente na visão dos trágicos. Em suas obras imortais, a Atè tinha um caráter de desastre, de desgraça objetiva. A loucura é por eles apresentada como um estado de desrazão produzido pela hybris: a desmedida, esse excesso no qual mergulha o homem quando, inconformado com as limitações de sua humanidade, acredita ser tão poderoso quanto os deuses e passa a desconsiderar as leis daqueles e seus próprios limites.

Na hybris, o homem embriaga-se com sua própria arrogância, mergulhando cego em um encadeamento de ações destemperadas que conduzem à sua inexorável perdição. Esta é a loucura aos olhos da tragédia: uma conseqüência dos atos insensatos dos homens.

10. P. Fédida. "Tradition tragique du psychopathologique. A propos du pathei mathos de l'Agamemnon", in P. Fédida. Crise et contre-transfert. Paris, PUF, 1992, pp. 19-36

11. M. Berlinck. "O que é a psicopatologia fundamental". Psicanálise e Universidade, $\mathrm{n}^{\mathrm{0}} 7$, 1997.

12. I. Pessotti. A loucura e as épocas. Rio de Janeiro, Ed. 34, 1994. 


\section{ARTIGOS}

Assim, para os trágicos gregos, o comportamento do homem começa a ser implicado na causa da loucura.

Pierre Fédida foi o primeiro a propor essa leitura esquiliana da psicopatologia inaugurando com ela a concepção de uma psicopatologia fundamental. Ele propõe que a natureza trágica do psicopatológico deve ser compreendida tal como apresentada no Agamenon de Ésquilo. No famoso trecho que abre esta peça, o coro, inquieto por causa dos maus presságios a respeito da volta de Agamenon no Palácio dos Atrides, canta:

Ele [Zeus] abriu aos homens as vias da prudência, dando-lhes como lei: "Sofrer para aprender" [pathei mathos]. Quando no meio do sono, sob o olhar do corpo, o doloroso remorso retorna, a sabedoria neles, apesar deles, penetra. E eis aí, creio, a violência benfazeja dos deuses sentados no timão celeste! ${ }^{13}$

O pathei mathos esquileano aparece aqui como a violência benfazeja dos deuses para com os homens, permitindo que algo da ordem da sabedoria surja do cerne de seus sofrimentos. Fundado sobre esta perspectiva, Pierre Fédida não hesita em propor a seguinte definição de psicopatológico: ...tal conhecimento formado na experiência íntima da paixão.

A psicopatologia fundamental visa, portanto, reinscrever a abordagem do sofrimento humano dentro dessa perspectiva, de modo a permitir que seja pensada uma clínica que resgate da paixão e do sofrimento sua capacidade geradora de sabedoria. Ao lado das perspectivas anteriores já indicadas: a de ser responsável por um trabalho de constante delimitação teórica entre as diversas disciplinas envolvidas no campo da psicopatologia - o que implica uma perspectiva histórica e crítica - e a de realizar a teorização do papel dos modelos e paradigmas na constituição tanto do campo da psicopatologia quanto do dispositivo epistemológico de formalização do objeto psicopatológico, surge aqui a terceira tarefa principal que concebemos para a Psicopatologia Fundamental: a de resgate da dimensão de implicação subjetiva na constituição do sofrimento psíquico e estudo das perspectivas clínicas decorrentes de tal postura ético-epistemológica.

Vê-se, assim, com este apanhado fragmentário que acabamos de realizar, que a tarefa de especificação da psicopatologia fundamental é ampla e está, em sua maior parte, ainda por fazer. O mesmo se aplica à delimitação de seu objeto psicopatológico que deve contemplar a um só tempo as vicissitudes da modelização em psicopatologia e a incidência da subjetividade no sofrimento psíquico. Contudo, o própria possibilidade contemporânea de avanço da psicopatologia passa por essas graves questões que a psicopatologia fundamental começa a levantar e, quem sabe, no futuro, a propor respostas.

13. Ésquilo. "Agamemnon” (176-183), in Tragédies. Trad. Paul Manzon. Paris, Gallimard, 1982, pp. 264-265. 


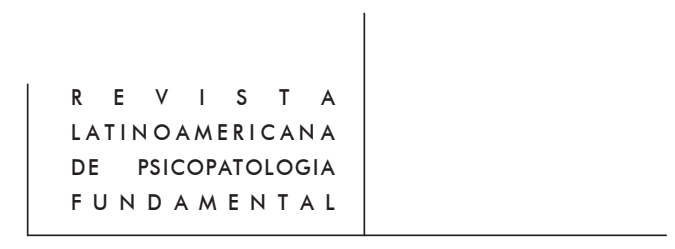

\section{Resumos}

Este trabajo trata de situar la Psicopatologia Fundamental en relación al contexto actual de la psicopatologia y delimitar su ámbito científico en aquello que propone de original en la discusión psicopatológica. El campo de la psicopatologia es inicialmente estudiado en relación a la formalización propuesta por Karl Jaspers en términos de una psicopatologia general. A seguir, se discute la incidencia específica del psicoanalisis en este debate.

Es propuesto que la tarea de la psicopatologia fundamental tiene tres frentes principales: 1) el trabajo de constante delimitación teórica entre las diversas disciplinas envueltas en el campo de la psicopatologia; lo cual implica una perspectiva histórica y crítica 2) teorización del papel de los modelos y paradigmas en la constituición tanto del campo de la psicopatologia cuanto del dispositivo epistemológico de formalización del objeto psicopatológico 3) resgate de la dimensión de implicación subjetiva en la constituición del sufrimiento psíquico y el estudio de las perspectivas clínicas resultante de tal postura ético-epistemológica.

This article seeks to position Fundamental Psychopathology in relation to the current psychopathological context and to delimitate its scienific scope in terms of that which it proposes as original in psychopathological discussions.

The psychopathological field is initially studied in terms of Karl Jasper's formalization of a general psychopathology, followed by a discussion about the specific incidence psycho-analysis has in this debate.

The article proposes that fundamental psychopathology's task is divided into three main fronts: 1) the task of constant theoretical delimitation among the different disciplines involved in the psychopathological field, implying a historical and critical perspective 2) theorization regarding the role of models and paradigms in the constitution of both the psychopathological field and the epistemological tools employed in the formalization of the psychopathological object 3) rescue of the dimension of subjective implications in the constitution of psychic suffering and the study of clinical perspectives emanating from such ethical-epistemological perspectives. 